\title{
Five years of cooperation: EURAPA and Springer Publishers-state of the art, changes, and future development
}

\author{
Heinz Mechling
}

Published online: 12 August 2010

(C) European Group for Research into Elderly and Physical Activity (EGREPA) 2010

The first volume of European Review of Aging and Physical Activity (EURAPA) was launched on occasion of the 6th World Congress on Aging and Physical Activity in London Ontario, Canada in 2004 as the official journal of European Group for Research into Elderly and Physical Activity (EGREPA; www.egrepa.org). In the beginning, this was only the society's initiative to get started. The decision for publishing EURAPA with Springer Publishers was taken in 2005. The first issue, Volume 3, Number 1, appeared in May 2006 [1,2].

This means 5 years of continuing cooperation. Five years of development of a scientific journal opens the opportunity to pause for a moment and to look back on what has been reached but at the same time to look forward to future requirements and developments.

Analyzing what has been reached and considering the common objectives of editors and publisher, we reached agreements on some points which don't have to be changed and some points that must be changed.

Before listing some changes, let me start with some excellent news which reached EURAPA in June 2010. Thomson and Reuters released the new impact factors (IF) for indexed journals. EURAPA has got IF for the first time - it is 0.550 . Therefore there is no need to change the journal's title, it will remain the official journal of EGREPA and its general policy and subject will be maintained. The scientific access to the field of aging and physical activity is still developing tremendously fast. Moreover, research

H. Mechling $(\bowtie)$

Institute of Movement Gerontology and Sport Gerontology,

German Sport University Cologne,

50933 Cologne, Germany

e-mail: mechling@dshs-koeln.de results concerning this topic are of highest social relevance and at the same time this topic is also increasingly developing into an explosive political subject.

EURAPA meanwhile has been well established and accepted as a peer-reviewed journal. With the new Springer subscription models via consortia deals, EURAPA is now available in thousands of institutions and several million computers around the world. EURAPA had 6,797 downloads in 2009 and EURAPA's rejection rate of manuscripts submitted in 2009 was exactly at $50 \%$.

In order to meet present and future challenges, some adjustments and changes will nevertheless be necessary:

- Starting with Volume 8, Number 1, 2011 EURAPA will be published only in electronic version.

- Your full paper will again be immediately available online via internet after publication (accepted by reviewers and decided by editors).

- Though EURAPA will still have a strong focus on review articles (systematic, academic, tutorial) in biomedical and behavioral science, we will accept original research papers starting with 2011.

- Also starting with 2011, we will accept papers on new manuscript categories as:

theoretical and methodological articles [e.g. 3, 4], research letters,

brief reports,

case reports,

reports on examples of good practice and practice concepts, commentaries and letters to the editors, guest editors and guest editorials.

Information on new manuscript categories will be integrated in our general information and instructions for 
authors in 2011 (www.egrepa.org or www.eurapa.org). If you plan to submit a paper, please read the instructions for authors in the EURAPA website.

Changes in the Editorial Board of EURAPA will be necessary in the near future. We therefore welcome proposals from our authors, subscribers, and readers for new Board Members to the Editors in Chief. Personal applications will also be possible. Expected commitments for editorial board members is to support the editors in canvassing authors, review one paper a year and submit one paper every 2 years.

If you are interested in the position of reviewer for our journal, please send us a short list of your fields. We will integrate you in our list of reviewers and send you just 1-2 manuscripts per year.

This issue is the last printed issue of EURAPA which to a certain degree is a special issue for the 12th EGREPA International Conference from 23-25 September 2010 in Prague. The contribution by C. Breuer anticipates another special issue on "Socio-economic aspects of physical activity and aging". Two more special issues with different behavioral and biomedical topics will follow.

In my personal judgment, the demographic development in our societies will necessitate the advancement of knowledge for improving practice through research in the following fields: safe mobility including fall prevention, assisted living in different dwelling situations, preventive and therapeutical programs; bionics, robotics, prosthetics, and ergonomic aids and physical activity will be of growing relevance [5].

The editors are well aware that the impact factor is a measure of the quality and relevance of papers published.
Therefore, we are delighted that EURAPA has been given an IF in 2010. This is regarded as a tribute to the work of the editorial team and the referees to improve the manuscripts submitted. The editorial team nevertheless would like to reassure readers that despite IF, we will also consider contributions of superordinate relevance and interest.

Thanks and appreciation also goes to the publisher and the responsible editors. The responsibility moved in 2010 from Gabriele Schröder to Ruth Cranks. We have enjoyed very much working with Gabriele Schröder during the past 5 years and look forward to our further cooperation with Ruth Cranks.

We also look forward to the future development of EURAPA and hope that the IF will encourage authors to consider submitting their most important work to EURAPA.

\section{References}

1. Mechling H (2006) Editorial EURAPA 2006-1. Eur Rev Aging Phys Act 3:1-2

2. Mechling $H$ (2007) Editorial-Aging and physical activity in the focus of science. Eur Rev Aging Phys Act 4:1-2

3. Baltes PB, Reuter-Lorenz P, Rösler F (eds) (2006) Lifespan development and the brain. Cambridge University Press, Cambridge

4. Li S-C (2006) Biocultural co-construction of lifespan development. In: Baltes PB, Reuter-Lorenz P, Rösler F (eds) Lifespan development and the brain. Cambridge University Press, Cambridge, pp $40-57$

5. Kane RA, Wilson KB (2007) Improving practice through research in and about assisted living: implications for a research agenda. The Gerontologist 47(Special Issue III):4-7 